\title{
ACESSIBILIDADE: UM DOS CAMINHOS PARA AUXILIAR NA INCLUSÃO
}

\author{
Eliza Dieko Oshiro TANAKA ${ }^{1}$
}

MANZINI, E. J. (Org.) Inclusão e Acessibilidade. Marilia: ABPEE, 2006.

Desde a aprovação da Declaração de Salamanca, em 1994, questões referentes a teorias e práticas inclusivas vêm sendo incessantemente discutidas tanto por educadores e órgãos que tratam da educação de pessoas com necessidades educacionais especiais, por empregadores e organismos que visam à colocação dessa população no trabalho, quanto pela sociedade de um modo geral. A partir de 1999, com a aprovação da portaria $\mathrm{n}^{\circ} 1.679$, o tema acessibilidade também passou a fazer parte do cenário dessas discussões, pois o direito de ir e vir tornou-se um elemento importante para auxiliar na inclusão social.

A VIII Jornada de Educação especial, que ocorreu de 8 a 11 de maio de 2006, promovida pelo Departamento de Educação Especial da Unesp, Campus de Marília foi, sem dúvida, um acontecimento de peso para a realização dessas discussões, pois nesse espaço os profissionais e pesquisadores tiveram a oportunidade de debater diferentes questões relacionadas ao eixo temático inclusão e acessibilidade e, além disso, disseminar suas produções científicas e divulgar as experiências desenvolvidas na área.

Os resultados desses debates estão apresentados no livro Inclusão $e$ Acessibilidade, organizado pelo Dr. Eduardo José Manzini. Essa obra é composta de 15 capítulos, distribuídos em sete temas.

O capítulo inicial apresenta uma experiência internacional ocorrida na Índia e África do Sul. A autora, a partir da realidade desses países, busca uma fonte de inspiração para a refletir sobre a inclusão no contexto brasileiro.

O tema Formação de Professores congrega dois capítulos, sendo que em um deles a autora analisa como essa formação vem ocorrendo, por meio da investigação junto a cursos de especialização, atualização, aperfeiçoamento desenvolvidos por instituições de ensino superior, Secretarias de Educação ou pelas próprias escolas. No outro é discutida a possibilidade de utilizar o trabalho colaborativo como estratégia para favorecer a inclusão de alunos com necessidades

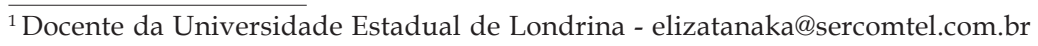


educacionais especiais. Esse modelo envolve a atuação compartilhada entre professores, administradores da escola, sistema escolar e comunidade, no planejamento, instrução e avaliação do aluno com necessidades especiais.

Dentro do tema Práticas Pedagógicas num Enfoque Inclusivo são apresentados três capítulos. No primeiro, a autora aborda o papel das práticas pedagógicas para a inserção do ser humano no mundo simbólico ou cultural; no segundo, é feita uma retrospectiva sobre os documentos voltados à garantia dos direitos sexuais das pessoas com deficiência, tentando analisar os fatores que dificultam a concretização desses direitos, e no terceiro, é analisada a prática pedagógica presentes na classe comum e especial como fonte de apropriação e cultura e as implicações que as contradições existentes no espaço escolar podem trazer para a inserção sócio-cultural desses alunos.

O tema Políticas em Educação Especial é apresentado em dois capítulos, sendo que no primeiro é discutida a perspectiva da educação especial, dentro de um enfoque inclusivo, a partir de um conjunto de estratégias definidas para o ensino regular, e as mudanças que devem ocorrer concomitantemente ao preparo dos professores e gestores para a inclusão. No outro, a autora faz referências às dimensões envolvidas na definição de uma política de educação especial, que deve resultar de discussões envolvendo a sociedade e da análise crítica dos aspectos filosóficos ideológicos, situacionais e pedagógicos.

No capítulo que compõe o tema Tecnologia Assistiva em Educação Especial, o autor discute questões metodológicas, de cunho pedagógico e computacional, necessárias para especificar e implementar a ferramenta Xlupa, que consiste num software livre de apoio educacional para pessoas com baixa visão.

O tema Acessibilidade e Recursos Para a Inclusão Escolar são discutidos em dois capítulos. No primeiro, a autora traz reflexões sobre a importância das imagens, signos, símbolos como recurso de apoio ao ensino-aprendizagem, reforçando a idéia que a comunicação alternativa suplementar requer a sua inserção social para tornar-se um instrumento de comunicação e interação e constituição de significados. Já no segundo capítulo é discutida a importância da formação continuada dos professores, em parceria com uma equipe de apoio, visando a busca de caminhos alternativos para sensibilizar os profissionais a compreenderem o aluno, a sua forma de pensar e a sua maneira de aprender falar e escrever.

O tema (Des) institucionalização da deficiência é composto por dois capítulos, num deles é ressaltada a função dos serviços terapêuticos em conjunto com os programas educacionais como meio de promoção do desenvolvimento e integração social da pessoa com deficiência e a necessidade de políticas públicas de atenção a essa população. No outro é realizado um breve relato histórico sobre os modelos de atendimento à pessoa com deficiência, desde a segregação total até a inclusão, e discutido o papel das organizações que prestam serviço a essa população como mediadoras da formulação de políticas sociais e a necessidade da 
sua mudança para alcançar uma sociedade mais inclusiva.

No último tema Trabalho e Deficiência, representado por dois capítulos, primeiramente é discutido a inclusão da pessoa com deficiência no âmbito das mudanças econômicas, políticas e sociais e proposto o desenvolvimento de políticas voltadas para a remoção de barreiras e estimulação das empresas para a contratação de pessoas com deficiência. No outro capítulo, o autor analisa os aspectos sociais, econômicos, culturais e psicológicos que determinam a exclusão da pessoa com deficiência do mundo do trabalho e do exercício da autonomia e da independência.

Por fim, é importante ressaltar que o livro lançado durante o evento mostra o impacto e a abrangência dos debates gerados na ocasião e, além disso, atesta a maturidade acadêmica alcançada nas pesquisas que tratam da inclusão da pessoa com necessidades especiais e a acessibilidade como um caminho auxiliar na sua realização. 
TANAKA, E. D. O. 